\title{
RHINOLOGY
}

\section{Sphenoidotomy kinetics in patients with chronic rhinosinusitis without nasal polyps}

\section{Cinetica della sfenoidotomia nei pazienti affetti da rinosinusite cronica non associata a poliposi nasale}

\author{
Panagiotis D. Pyriochos ${ }^{1}$, Konstantinos Markou' ${ }^{1}$, Jannis Constantinidis², Iordanis Konstantinidis ${ }^{1}$ \\ ${ }^{1} 2^{\text {nd }}$ Academic ORL Department, Papageorgiou Hospital, Aristotle University, Thessaloniki, Greece; ${ }^{2} 1{ }^{\text {st }}$ Academic ORL Department, \\ AHEPA Hospital, Aristotle University, Thessaloniki, Greece
}

\section{SUMMARY}

Objective. Stenosed sphenoid sinus ostia are among the most common findings in revision endoscopic sinus surgery. This study sought to identify the optimal intraoperative sphenoidotomy size for prevention of postoperative stenosis.

Methods. 32 patients affected by chronic rhinosinusitis not associated with nasal polyps (CRSsNP) underwent 52 sphenoidotomies. Sphenoidotomy size was assessed using a ruler intraoperatively and at the first, third and sixth months postoperatively. Ostia sizes, SNOT22 questionnaire findings, episodes of recurrent sinusitis and need for revision surgery were recorded.

Results. All sphenoidotomies exhibited a significant size reduction (mean $43.4 \pm 6.8 \%$ ) at the first month postoperatively, with a tendency to enlarge at 3 months and stabilise at 6 months. Ostia larger than $61.3 \mathrm{~mm}^{2}$ did not exhibit stenoses postoperatively. Stenosis was observed in 11 sphenoidotomies (21.2\%); however, only five presented with recurrent symptoms (9.6\%), while three required revision sphenoid surgery $(5.8 \%)$.

Conclusions. Sphenoidotomy size significantly reduced during the first postoperative month and then stabilised. A baseline sphenoidotomy size of $61.3 \mathrm{~mm}^{2}$ at the time of the operation seemed sufficient to prevent ostium stenosis. Half of stenosed ostia presented with recurrent symptoms.

KEY WORDS: sphenoidotomy, stenosis, kinetics, CRSsNP, curette

\section{RIASSUNTO}

Obiettivo. Le stenosi degli osti sfenoidali sono tra i reperti più comuni nelle revisioni chirurgiche endoscopiche a carico di questo seno paranasale. Questo studio ha cercato di identificare la dimensione ottimale della sfenoidotomia, misurata intraoperatoriamente, per prevenire la stenosi postoperatoria.

Metodi. Trentadue pazienti affetti da rinosinusite cronica non associata a poliposi nasale (CRSSNP) sono stati sottoposti a sfenoidotomia (52 sfenoidotomie). La dimensione della sfenoidotomia è stata valutata utilizzando un righello intraoperatoriamente, al primo, terzo e sesto mese dopo l'intervento. Sono state registrate le dimensioni degli osti, i risultati del questionario SNOT-22, gli eventi di recidiva di sinusite e la necessità di un intervento chirurgico di revisione.

Risultati. Tutte le sfenoidotomie $(n=52)$ hanno mostrato una significativa riduzione delle dimensioni (media 43,4 $\pm 6,8 \%$ ) al primo mese dopo l'intervento, con una tendenza ad allargarsi a tre mesi e stabilizzarsi a sei mesi. Gli osti più grandi di $61,3 \mathrm{~mm}^{2}$ non hanno mostrato stenosi dopo l'intervento. La stenosi è stata osservata in 11 sfenoidotomie (21,2\%); tuttavia, solo cinque erano associati a sintomi ostruttivi (9,6\%), mentre in tre casi è stato necessario un intervento di revisione dello sfenoide $(5,8 \%)$.

Conclusioni. La dimensione della sfenoidotomia si è ridotta significativamente durante il primo mese postoperatorio, e successivamente si è stabilizzata. Una dimensione della sfenoidotomia al basale di 61,3 $\mathrm{mm}^{2}$ sembra prevenire la stenosi dell'ostio. La metà delle stenosi degli osti sfenoidali sembrerebbe associarsi a sintomi disventilativi.

PAROLE CHIAVE: sfenoidotomia, stenosi, cinetica, CRSsNP, curette
Received: March 6, 2021

Accepted: September 14, 2021

Published online: February 7, 2022

Correspondence

Iordanis Konstantinidis

3A Kapetan Kotta str, Panorama, Thessaloniki, Greece

Tel. +30 6973229525

E-mail: jordan_orl@hotmail.com

How to cite this article: Pyriochos PD, Markou K, Constantinidis J, et al. Sphenoidotomy kinetics in patients with chronic rhinosinusitis without nasal polyps. Acta Otorhinolaryngol Ital 2022;42:55-62. https://doi. org/10.14639/0392-100X-N1545

() Società Italiana di Otorinolaringoiatria e Chirurgia Cervico-Facciale

\section{(c) (1) () $\odot$}

This is an open access article distributed in accordance with the CC-BY-NC-ND (Creative Commons Attribution-NonCommercial-NoDerivatives 4.0 International) license. The article can be used by giving appropriate credit and mentioning the license, but only for non-commercial purposes and only in the original version. For further information: https:// creativecommons.org/licenses/by-nc-nd/4.0/deed.en 


\section{Introduction}

Endoscopic sphenoidotomy, which can be performed transethmoidally or transnasally, is the preferred surgical approach for the treatment of sphenoid sinus diseases, largely due to its excellent outcomes and low morbidity rate ${ }^{1}$. The long-term outcomes of endoscopic sphenoidotomy in the context of isolated sphenoid sinus diseases have been found to have patency rates greater than $90 \%{ }^{1}$. However, chronic rhinosinusitis (CRS) with sphenoid involvement is more challenging to treat. In fact, although CRS is the least common sinus disease, additional surgery is required in 34\%-65\% of revision cases due to persistent or recurrent disease and stenosis ${ }^{1}$.

The main causes of persistent sphenoid disease are scarring and/or thick neo-osteogenic bone in the ostium area, failure to open the sphenoid sinus (e.g. mistaking the Onodi cell for the sphenoid sinus) and recirculation in the transethmoidal approaches ${ }^{2}$. Given that blocked or significantly stenosed sphenoid sinus ostia are identified in $65.9 \%$ of patients who undergo revision endoscopic sinus surgery (ESS), the postoperative assessment of the patency and size of the ostium is highly important ${ }^{3}$. Yet, despite advances in our understanding of the pathophysiology of CRS, the optimal sphenoidotomy size at the time of the surgery remains unclear ${ }^{4,5}$.

This prospective study sought to evaluate the size of the sphenoidotomy within the first six months after surgery as well as to determine whether the identified intraoperative sinus ostium size predisposes patients with CRS without polyps (CRSsNP) to recurrence of disease.

\section{Materials and methods}

\section{Patients}

Patients between 18 and 75 years who were undergoing functional ESS for CRSsNP were included in the present study. Patients with nasal polyps, allergic fungal sinusitis, isolated sphenoid sinusitis, a history of previous sinus surgery (including sphenoid sinus surgery), tumours or who were undergoing trans-sphenoidal neurosurgical procedures were excluded. Initially, 50 patients were included. Later, patients who underwent transethmoidal sphenoidotomies (five patients), who needed posterior ethmoidectomy (four patients) and who developed postoperative recurrent ethmoid sinusitis (three patients), which all complicated the healing process of the sphenoid ostium, were excluded from the study. Among the remaining 38 patients, two did not complete the follow-up assessment. Finally, another four patients who exhibited poor compliance with their postoperative care, including failing to perform the daily nasal rinsing for a period of over a week, were also ex- cluded from the study (compliance rate: $88.9 \%, 32$ of 36 patients).

In terms of preoperative computed tomography (CT) scans, all patients exhibited at least partial opacification of one sphenoid sinus. Each sinus was categorised according to the Lund-Mackay (LM) system, a well-validated staging system for CRS, and graded between zero and two (zero: no abnormality, one: partial opacification, two: total opacification) ${ }^{6}$.

Patients had been referred for ESS after failure of maximal medical treatment to control symptoms. Thus, the criterion for surgery was the severity of symptoms, as reported using the Sino-Nasal Outcome Test-22 (SNOT-22) questionnaire (score $>20$ ), accompanied by imaging findings with an LM score of $\geq 1^{7}$.

\section{Surgery}

All surgical procedures were performed under general anaesthesia by the same surgeon over a 2.5 -year period. The extent of sinus surgery performed for each patient was determined by the amount and location of their sinus disease. Thus, in accordance with the Messerklinger principles, all the patients in the study group underwent at least middle meatal antrostomy, anterior ethmoidectomy and transnasal sphenoidotomy. The additional surgery, which was performed when necessary, included frontal sinusotomy and posterior ethmoidectomy. However, patients who required posterior ethmoidectomy were excluded from the present study, whether or not they underwent transnasal or transethmoidal sphenoidotomy.

Each patient in the study group underwent at least one transnasal sphenoidotomy with a minimum diameter of $5 \mathrm{~mm}\left(19.625 \mathrm{~mm}^{2}\right.$ area), with this size area being considered the criterion for stenosis. To minimise the risk of bias, each sphenoidotomy was performed using only conventional instrumentation (e.g. Kerrison forceps). In some cases, once the appropriate structures had been identified, the inferior third of the superior turbinate was resected to allow for identification of the sphenoid sinus natural ostium medial to it. The ostium was then widened medially towards the septum and inferiorly towards the posterior septal branch of the sphenopalatine artery. This was done without further manipulation of the superior turbinate to reduce the risk of skull base injury. In all cases, the sphenoidotomy was performed while protecting the surrounding mucosa, meaning that the operation resulted in an ostium without any uncovered bony edges. At the end of each surgical procedure, the sphenoidotomy size was assessed by using a curved ear curette $\left(90^{\circ}, 5 \mathrm{~mm}\right.$ internal diameter) as a ruler (Fig. 1A).

Endoscopic images were taken and stored in a computer. 


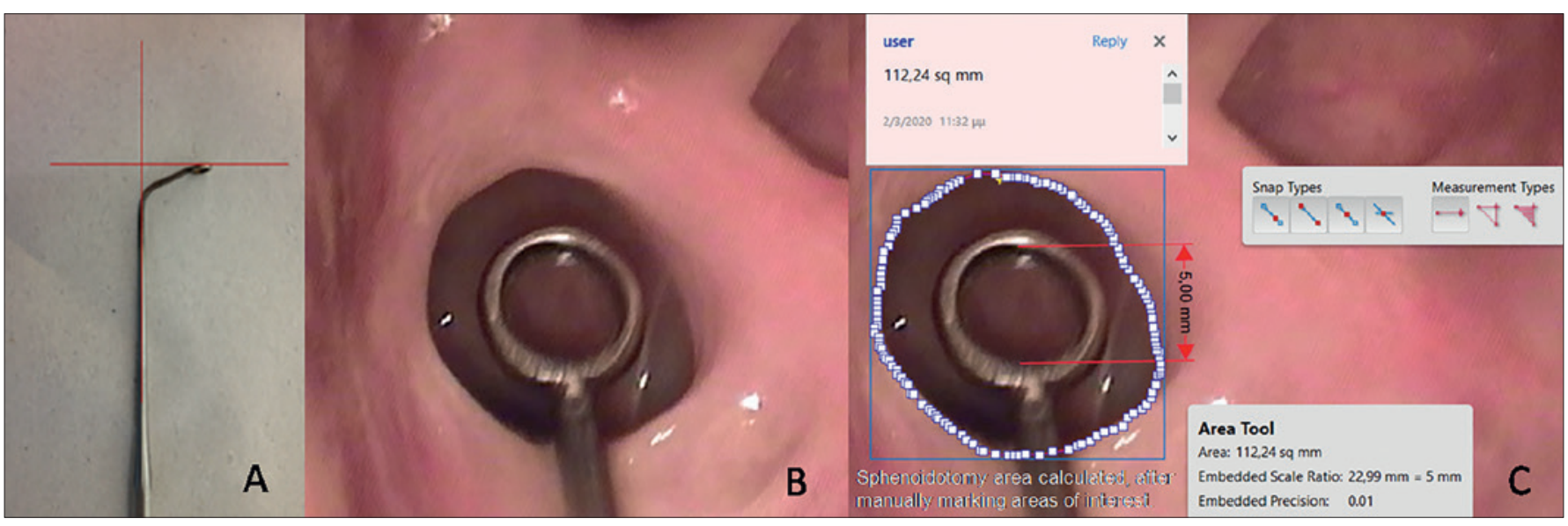

Figure 1. (A) The curved $90^{\circ}$ ear curette with an internal diameter of $5 \mathrm{~mm}$ used as a ruler. (B) Endoscopic image of a left sphenoidotomy. (C) Endoscopic image of the same sphenoidotomy, as measured in Adobe Acrobat.

After each procedure, both nasal cavities were packed for 24 hours.

\section{Postoperative care}

All patients were discharged with a 10-day course of oral doxycycline, nasal steroids (budesonide, total daily dose of $400 \mathrm{mcg}$ ) and nasal saline irrigation, which was to be performed at least twice daily for up to eight weeks. The postoperative removal of clots and crusts was performed endoscopically on a weekly basis for a period of four to six weeks if required. Follow-up appointments were scheduled at one, three and six months postoperatively.

\section{Measurements}

The sphenoidotomy size was assessed intraoperatively and at the three follow-up appointments (first, third and sixth postoperative months) using a curved ear curette with a 5 $\mathrm{mm}$ internal diameter. All the intraoperative and postoperative endoscopic images were captured using the same $0^{\circ}, 3.5 \mathrm{~mm}$ nasal endoscope (Karl Storz Co., Tuttlingen, Germany). We placed the probe in the same vertical plane as the sphenoidotomy and close to the centre of the endoscope's field in order to minimise the visuospatial distortion.

The stenosis assessment was performed when the endoscopic image of the probe most closely resembled a circle. Under these conditions, the endoscopic images can be measured accurately and in a reproducible manner, as the visuospatial error fell below $5 \%{ }^{8}$. In borderline cases, to achieve precise measurements, the probe should occupy more than $40 \%$ of the endoscopic field.

The stored endoscopic images were measured by a blinded observer (the last author) to determine the size of the sphenoid ostium. More specifically, the measurements were performed using Adobe Acrobat Pro Document Cloud software (version 2018.009.20050) (Adobe Inc., San Jose, California, United States [US]), while the areas of interest were manually marked. Using Adobe tools for area measurements, the sphenoidotomy size was automatically calculated after adjusting the measurements for the known curette diameter (embedded scale ratio) (Fig. 1B). The curette area could easily be found using the formula $\mathrm{A}=\pi \mathrm{r}^{2}$, where $\mathrm{A}$ is the area and $\mathrm{r}$ is the radius $(2.5 \mathrm{~mm}): 19.625 \mathrm{~mm}^{2}$. Every sphenoidotomy with an area measurement $\leq 19.625 \mathrm{~mm}^{2}$ was considered stenotic.

The SNOT-22 questionnaire was used to assess patients' subjective symptoms at baseline and during follow-up appointments ${ }^{9}$. We also assessed the number of patients who had changes in their SNOT-22 scores above the minimal clinically important difference (MCID) for surgically treated CRS patients (9.0 points), as suggested by Hopkins et al. ${ }^{10}$. The patients' medical records were also reviewed for episodes of postoperative recurrent sinusitis and the need for revision surgery.

The patients were defined as being symptomatic postoperatively if their SNOT-22 scores remained $>20$ at their last follow-up appointment and pus or thick secretions from their sphenoid sinus ostium were observed (with no evidence of ethmoidal cavity inflammation). No further imaging studies were performed postoperatively.

\section{Statistical analysis}

The results were analysed using Statistical Package for the Social Sciences (SPSS) version 16.0 for Windows (SPSS Inc., Chicago, Illinois, US). 
The sample size calculation was based on the following parameters: an acceptable error alpha of 0.05; an acceptable error beta of 0.10 ; and a clinical difference of $3 \mathrm{~mm}$ in diameter and a standard deviation $(\mathrm{SD}) \pm 1.1$, which corresponds to an area of $28.26 \mathrm{~mm}^{2}$ and a $\mathrm{SD} \pm 3.8$. According to Douglas Altman's nomogram, the adequate minimum number of patients for a study with $85 \%$ power equates to 28 sphenoidotomies ${ }^{11}$.

All descriptive statistics are presented in the text as the mean values $\pm \mathrm{SD}$ of the means. The comparisons among the ostium areas during the follow-up period were performed using a paired t-test, while the correlations between the measurements and descriptive statistics were determined using the Spearman rank correlation coefficients. The statistical significance level was set at 0.05.

\section{Results}

\section{Patient characteristics}

Thirty-two CRSsNP patients (18 males and 14 females) with a mean age of 46.1 years (range: $22-73$ years) who underwent ESS at a tertiary centre were included in this prospective, non-controlled study, which was conducted over a period of 2.5 years. Demographic statistics concerning the patients are presented in Table I.

\section{Sphenoidotomy kinetics}

In total, 52 nasal cavities (20 bilateral and 12 unilateral sphenoidotomies) were assessed at the first, third and sixth months postoperatively. The shape of each patient's ostia at the end of the operation was either oval $(n=27)$ or round $(n=25)$.

During the final postoperative follow-up appointments, 11 of the 52 sphenoidotomies were found to be stenotic (21.2\%), which related to eight of the 32 operated patients $(25 \%)$. Five of those patients had unilateral stenosis, while three had bilateral stenosis.

Table I. Demographic statistics of the CRSsNP patient cohort.

\begin{tabular}{lc} 
Total group (n) & 50 \\
Included & 32 \\
Male & $18(56 \%)$ \\
Female & $14(44 \%)$ \\
Mean age (age range) & $46.1(22-73)$ \\
Asthma & $1(3 \%)$ \\
Diabetes & $2(6 \%)$ \\
Smoking & $6(18 \%)$ \\
Transnasal sphenoidotomy & 32 \\
i) Bilateral & 20 \\
ii) Unilateral & 12 \\
\hline
\end{tabular}

n: number of patients.
The presence of sphenoidotomy stenosis did not correlate with gender, age, comorbidities or ostium shape (all $\mathrm{r}<0.2$, $\mathrm{p}>0.05)$. The correlations are presented in Table II.

The mean sphenoidotomy area in our cohort during baseline assessments (end of the operation) was $67.5 \pm 14.6$ $\mathrm{mm}^{2}$. A significant decrease in this size (mean size: 38.2 $\pm 11.3 \mathrm{~mm}^{2}, \mathrm{p}<0.001$ ) was observed during the first postoperative month (percentage decrease: $43.4 \% \pm 6.8$ ), with a slight enlargement being seen at three months $(9.1 \% \pm$ 2.7) and stabilisation being noted at six months (Fig. 2). Figure 3 presents an example of the aforementioned sphenoidotomy kinetics in a patient from our cohort.

The stenotic sphenoidotomies had a mean baseline size of $38.8 \pm 8.8 \mathrm{~mm}^{2}$, which was significantly smaller than the mean baseline size of the sphenoidotomies that did not develop stenosis $\left(76 \pm 14.7 \mathrm{~mm}^{2}, \mathrm{p}<0.001\right)$. Notably, at the end of the surgery, all the sphenoidotomies were greater than $19.625 \mathrm{~mm}^{2}$ in area, which was the criterion for stenosis.

A comparison of the kinetics between the stenotic and nonstenotic sphenoidotomies postoperatively (Fig. 4) revealed initially similar patterns, with a significant decrease being seen in the first month for both groups. However, the stenotic sphenoidotomies exhibited a slight worsening in size between the one-month $\left(18 \pm 5.1 \mathrm{~mm}^{2}\right)$, three-month $\left(16.6 \pm 5.5 \mathrm{~mm}^{2}\right)$ and six-month postoperative follow-up appointments $\left(12.6 \pm 4.5 \mathrm{~mm}^{2}\right)$. The non-stenotic sphenoidotomies exhibited an increase in size at the three-month follow-up appointment $(9.92 \% \pm 2.1)$ and no change at the six-month appointment. All 24 patients with non-stenotic sphenoidotomy remained asymptomatic during the followup period.

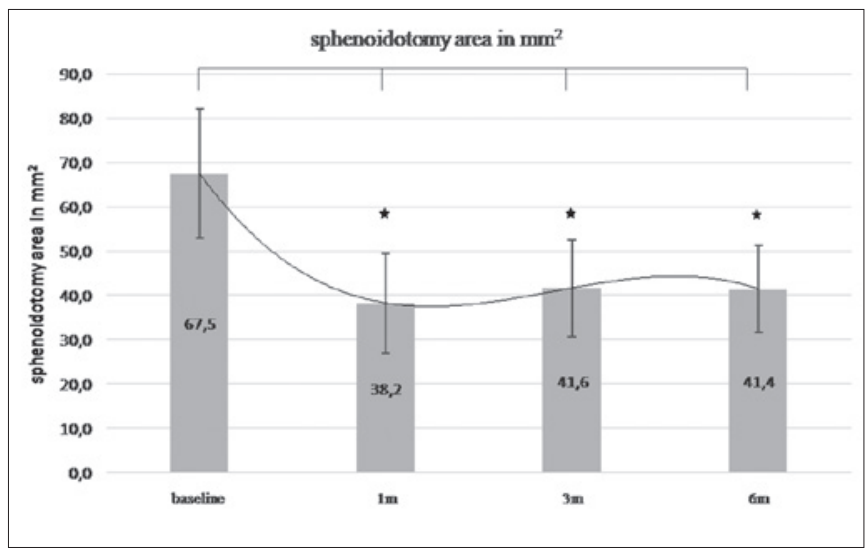

Figure 2. Sphenoidotomy size kinetics of the study group. Asterisks indicate the statistically significant size differences between the intraoperative and follow-up measurements. Polynomial trendline represents the measurement fluctuation. 
Table II. Correlations between the patient characteristics and stenosis (Spearman correlation test).

\begin{tabular}{|c|c|c|c|c|c|c|}
\hline & Age & Gender & Shape of ostium & Comorbidities & $\begin{array}{l}\text { Preop LM CT } \\
\text { score }\end{array}$ & Stenosis \\
\hline Age & & $\begin{array}{l}p=0.92 \\
r=0.17\end{array}$ & $\begin{array}{l}p=0.81 \\
r=0.11\end{array}$ & $\begin{array}{c}p=0.13 \\
r=0.1\end{array}$ & $\begin{array}{l}p=0.65 \\
r=0.18\end{array}$ & $\begin{array}{l}p=0.57 \\
r=0.12\end{array}$ \\
\hline Gender & $\begin{array}{l}p=0.92 \\
r=0.17\end{array}$ & & $\begin{array}{l}p=0.71 \\
r=0.13\end{array}$ & $\begin{array}{l}p=0.97 \\
r=0.11\end{array}$ & $\begin{array}{l}p=0.94 \\
r=0.08\end{array}$ & $\begin{array}{c}p=0.43 \\
r=0.1\end{array}$ \\
\hline Shape of ostium & $\begin{array}{l}p=0.81 \\
r=0.11\end{array}$ & $\begin{array}{l}p=0.71 \\
r=0.13\end{array}$ & & $\begin{array}{l}p=0.53 \\
r=0.16\end{array}$ & $\begin{array}{l}p=0.68 \\
r=0.15\end{array}$ & $\begin{array}{l}p=0.78 \\
r=0.13\end{array}$ \\
\hline Comorbidities & $\begin{array}{c}p=0.13 \\
r=0.1\end{array}$ & $\begin{array}{l}p=0.97 \\
r=0.11\end{array}$ & $\begin{array}{l}p=0.53 \\
r=0.16\end{array}$ & & $\begin{array}{l}p=0.47 \\
r=0.19\end{array}$ & $\begin{array}{l}p=0.11 \\
r=0.17\end{array}$ \\
\hline Preop LM CT score & $\begin{array}{l}p=0,65 \\
r=0,18\end{array}$ & $\begin{array}{l}p=0.94 \\
r=0.08\end{array}$ & $\begin{array}{l}p=0.68 \\
r=0.15\end{array}$ & $\begin{array}{l}p=0.47 \\
r=0.19\end{array}$ & & $\begin{array}{l}p=0.78 \\
r=0.19\end{array}$ \\
\hline Stenosis & $\begin{array}{l}p=0.57 \\
r=0.12\end{array}$ & $\begin{array}{c}p=0.43 \\
r=0.1\end{array}$ & $\begin{array}{l}p=0.78 \\
r=0.13\end{array}$ & $\begin{array}{l}p=0.11 \\
r=0.17\end{array}$ & $\begin{array}{l}p=0.78 \\
r=0.19\end{array}$ & \\
\hline
\end{tabular}

p: $p$ value; r: correlation coefficient; Preop LM CT score: Preoperative Lund-Mackay computed tomography score.
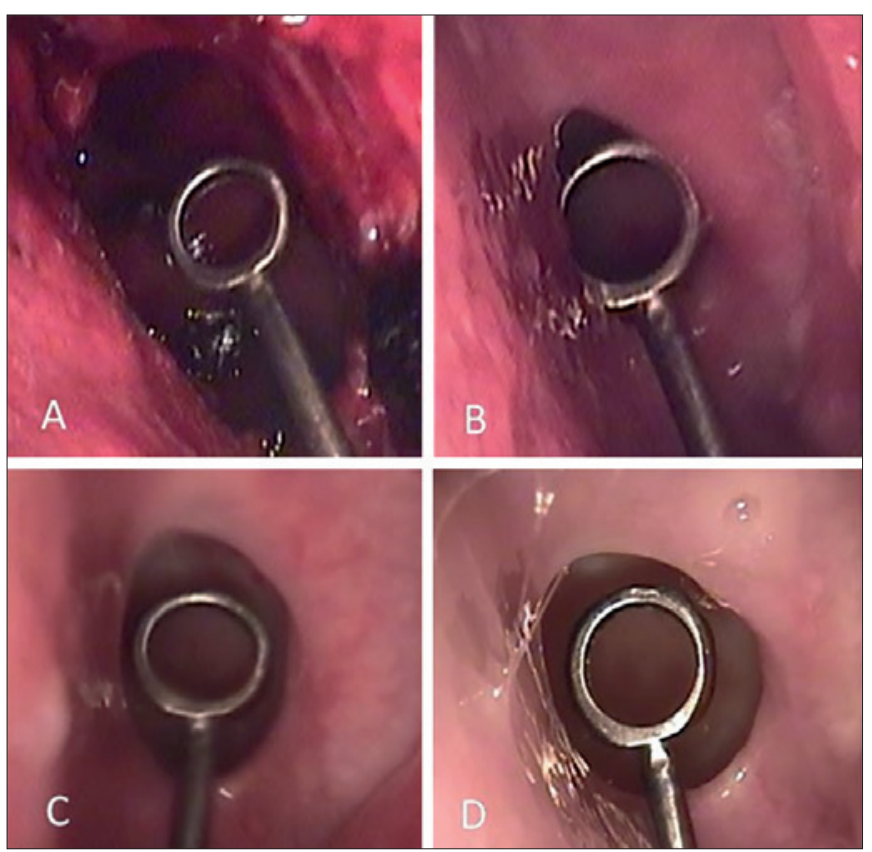

Figure 3. Endoscopic images of a non-stenotic left sphenoidotomy in a male patient from our cohort. The changes in size at every stage of the follow-up period are made clear by the ruler. (A) Sphenoidotomy at the end of the operation. (B) One month later. (C) Three months later. (D) Six months later.

\section{Outcomes of patients with stenosis}

The eight patients with stenosis were divided as follows: three asymptomatic and five with recurrent symptoms of sinusitis (SNOT-22 score $>20$ ). The three asymptomatic patients with stenosis were provided with close follow-up in accordance with a "wait and see" policy. Two of the five symptomatic patients with stenosis were successfully managed by further medical treatment (nasal steroids for an additional two months and a low dose of doxycycline [100 mg/

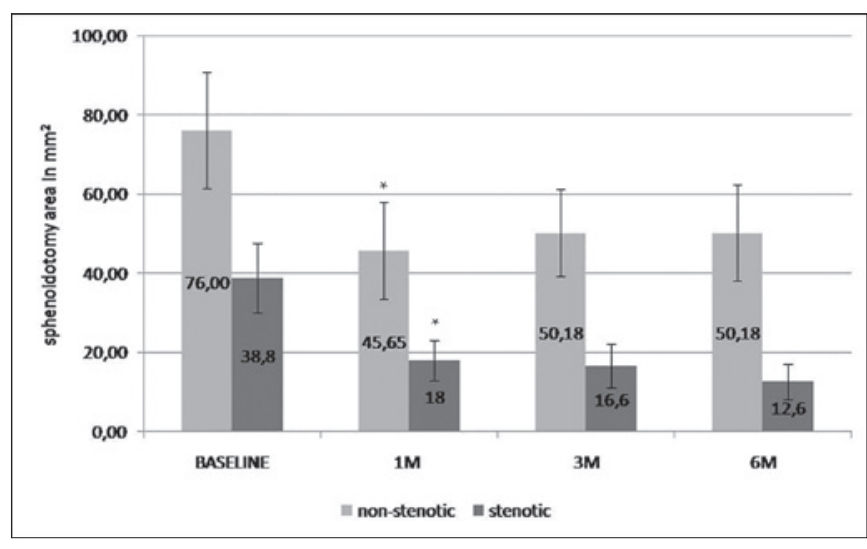

Figure 4. Comparison of the mean areas between stenotic and non-stenotic sphenoidotomies during the six-month follow-up period. Asterisks indicate the significant decrease in the sphenoidotomy sizes of both groups at the onemonth postoperative assessment $(p<0.001)$.

day] for ten weeks). However, the remaining three symptomatic patients with stenosis required further sphenoid sinus surgery due to the nearly complete blockage of the ostium and persistent sinusitis symptoms (the patients' ostium areas were $8 \mathrm{~mm}^{2}, 10 \mathrm{~mm}^{2}$ and $12 \mathrm{~mm}^{2}$, respectively). Thus, the revision surgery rate in our cohort was $5.8 \%$ (or three of 52 sphenoid sinuses). Revision surgery was planned for these three patients after the six-month follow-up period.

The mean baseline sphenoidotomy size of the five symptomatic patients was lower $\left(36.9 \pm 6.9 \mathrm{~mm}^{2}\right)$ than that of the three asymptomatic patients $\left(41.9 \pm 5.3 \mathrm{~mm}^{2}, \mathrm{p}=0.11\right)$, albeit without statistical significance. All sphenoidotomy area measurements are presented in Table III.

SNOT-22

The assessment of the SNOT-22 questionnaire findings 
Table III. Sphenoidotomy area $\left(\mathrm{mm}^{2}\right)$ measurements intraoperatively and at the first, third and sixth postoperative months

\begin{tabular}{lcccc} 
& Intraoperatively & First month & Third month & Sixth month \\
Study cohort & $67.5 \pm 14.6$ & $38.2 \pm 11.3$ & $41.6 \pm 10.9$ & $41.4 \pm 9.8$ \\
Non-stenotic & $76.0 \pm 14.7$ & $45.6 \pm 12.3$ & $50.2 \pm 11$ & $50.2 \pm 12.2$ \\
Stenotic & $38.8 \pm 8.8$ & $18.0 \pm 5.1$ & $16.6 \pm 5.5$ & $12.6 \pm 4.5$ \\
i) Symptomatic & $36.9 \pm 6.9$ & $16.1 \pm 3.2$ & $15.1 \pm 4.0$ & $11.0 \pm 2.9$ \\
ii) Asymptomatic & $41.9 \pm 5.3$ & $21.3 \pm 1.8$ & $18.6 \pm 3.5$ & $15.1 \pm 2.0$ \\
\hline
\end{tabular}

Data are expressed as Mean \pm Sd; Sd: standard deviation.

revealed a significant improvement in patients' symptom scores from a mean of $35.7 \pm 11.2$ preoperatively to a mean of $9.3 \pm 4.2$ at the sixth postoperative month. All the asymptomatic (stenotic and non-stenotic) patients had changes in their SNOT-22 symptom scores greater than a MCID of 9.0, without correlation between the postoperative SNOT-22 scores and the final sphenoidotomy sizes ${ }^{10}$. The three patients who required revision surgery had no significant improvement of their SNOT-22 scores, with their mean score being $23.5 \pm 5.8$ at the final follow-up appointment. The latter score mainly included symptoms from the nasal subdomain of the SNOT-22 questionnaire, including postnasal drip, thick secretions and stuffed nose, with a mean score of $18.3 \pm 2.4{ }^{12}$.

\section{LM CT score}

A comparison of the LM CT scores between the stenotic and non-stenotic cases did not reveal a significant difference (stenotic mean LM score of $12.3 \pm 1.8 v s$ non-stenotic mean LM score of $11.8 \pm 1.6, p=0.821$ ). The presence of stenosis was not correlated with the extent of the disease, as seen in relation to the preoperative LM CT score $(\mathrm{r}=$ $0.19, \mathrm{p}=0.78)$.

\section{Discussion}

Revision endoscopic surgery is required when medical treatment fails to manage persistent disease due to issues such as postoperative abnormal mucociliary transport, incomplete surgery, lateralised middle turbinate, synechiae and stenosed or blocked sinus ostium ${ }^{3}$. A blocked antrostomy is the most common anatomical finding in revision maxillary sinus surgery, as reported by Musy and Kountakis (39\% of their series) ${ }^{13}$. Although several studies have previously investigated the optimal antrostomy size for the maxillary sinus, finding that an ostium of at least $5 \mathrm{~mm}$ in diameter is necessary, the same is not true for the sphenoid sinus, as only a very limited body of literature is available ${ }^{14-16}$.

In a cadaveric study, Singhal et al. found that larger maxillary and sphenoid sinus ostia had significantly better ap- plications in terms of nasal lavage than smaller ones, suggesting that better saline penetration was obtained at an ostial diameter of $4.7 \mathrm{~mm}{ }^{15}$. However, other studies have suggested that a wider sinus ostium does not necessarily ensure appropriate drug application ${ }^{17,18}$.

Given that blocked sphenoid sinus ostia are identified in $65.9 \%$ of patients who undergo revision surgery, this study sought to assess the kinetics of the sphenoidotomy size and determine its effect on the course of the disease ${ }^{3}$. The present study had two major findings. First, the sphenoidotomy area decreased significantly (by $43.4 \%$ ) within the first postoperative month, with a small improvement in size and then stabilisation occurring during the next five months. Second, stenosis did not develop in patients with a large sphenoidotomy area at baseline $\left(>61.3 \mathrm{~mm}^{2}\right.$, approximately three times the ruler's size). This criterion represents the mean sphenoidotomy size in non-stenotic patients minus its $\operatorname{SD}\left(76-14.7 \mathrm{~mm}^{2}\right)$.

Wound healing following ESS represents a prolonged and complex process ${ }^{19}$. Limited data are available regarding alterations in the antrostomy size during the healing process ${ }^{20}$. However, the first six postoperative months are considered the most important in relation to the development of ostium stenosis ${ }^{19}$.

The finding of an initial rapid decrease in size during the follow-up period in the present study corresponds to the blood-crusting and obstructive-lymphedema phases of the wound-healing process. The subsequent increase in size during the third month and the stabilisation of the ostium size in the sixth month mainly reflect the phases involving mesenchymal growth and scar-tissue formation ${ }^{19}$. The significant decrease in the ostium size within the first month may indicate the importance of early postoperative care concerning the nasal cavity, such as nasal rinsing and meticulous debridement. Further studies are required to clarify the optimal medical treatment during this postoperative period, focusing on medications that could act in the early phases of wound healing. In addition, taking into account this early ostium shrinkage, surgeons may prefer to create larger ostia during surgery.

The use of a simple ear curette to assess the sphenoidotomy 
size, despite being quick and easily applicable in an operating room/clinical setting, remains an imprecise means of assessing the size of a sinus ostium. Ideally, software should be developed to facilitate the calculation of the sinusotomy size on site.

Based on the present results, it is difficult to suggest an optimal sphenoidotomy size due to the limited number of patients and the multifactorial nature of both the disease and wound-healing process. However, the data on non-stenotic patients (mean: $76 \pm 14.7 \mathrm{~mm}^{2}$ ) indicate that larger ostia may be safer when it comes to avoiding recurrent symptoms and the need for revision surgery.

The patients' subjective symptoms, measured using the SNOT-22 questionnaire, showed a significant improvement postoperatively in non-stenosed and asymptomatic stenotic cases, regardless of the postoperative sphenoidotomy size. On the contrary, significantly higher SNOT-22 scores $(>20)$ were found at the last follow-up appointment in the stenosed cases requiring surgery. These results may indicate that stenosis is not the only factor that contributes to persistent disease and, furthermore, that additional medical treatment may help to ensure a healthy sphenoid sinus despite the presence of a stenosed ostium.

A number of prior studies have explored techniques that may serve to prevent postoperative stenosis of the sphenoidotomy, albeit without performing measurements of the actual area size. Yu et al. suggested that powered instrumentation is more effective than conventional instruments in terms of treatment of isolated sphenoid sinus ${ }^{21}$. Our study cannot support this suggestion, as we used only conventional instruments; however, the use of powered instrumentation may cause osteitis, a factor known to contribute to the closure of the ostium. This issue remains controversial and further studies are required to provide clarification.

Another prior study proposed the use of the adjacent nasal mucosa as rotational tissue flaps covering the exposed bone of the neo-ostium, thereby minimising fibrosis and preventing the closure of the sinus ${ }^{22}$. The extent and size of the initial ostium were not reported, and the outcome was only approximately measured using suction tips of different widths. Similarly, Thompson et al. used a mini-nasoseptal flap to prevent ostium restenosis in a cohort of 9 patients with highly inflammatory sphenoid sinus pathologies, although they did not calculate the initial sphenoidotomy size ${ }^{23}$.

To the best of our knowledge, this is the first study to measure the sphenoid ostium size at the time of surgery and during the healing process. Despite the final sample size of the population requiring revision surgery being too small to make a meaningful comparison, the nearly complete blockage of the sphenoid ostium represented their main characteristic.
It must be recognised that the present study had several limitations. First, it included only patients with CRSsNP, meaning that the results do not provide information about patients with higher inflammatory loads, such as nasal polyposis or cystic fibrosis. In addition, patients with extended sinusitis involving the posterior ethmoids that required posterior ethmoidectomy, a procedure that can complicate the healing process of the sphenoid ostium, were excluded. Although isolated sphenoid sinusitis appears to be the ideal model for such a study, the disorder is rare and represents only a small proportion of CRS patients ${ }^{24}$. Given the aforementioned reasons, we limited our cohort to CRSsNP.

Further research is required to assess the other factors, besides the initial size, that contribute to ostium stenosis, including osteitis in revision cases or other underlying disorders (e.g., Wegener's disease). Additionally, mucociliary function, especially around the neo-ostium, may require special attention, as the sphenoid sinus works partially against gravity. Bearing in mind that the volume of the sinus and the size of the ostium clearly affect the pressure gradient between the nasal cavity and sinus, thereby playing an important role in the transport of gas and drugs, further studies are required to assess these factors ${ }^{25}$.

Although the method used for the ostium measurements is applicable for research purposes, it should be noted that it is difficult to apply in an operating room setting, where it is not possible to obtain accurate measurements without simultaneous software-based calculations.

\section{Conclusions}

The findings of the present study demonstrated that sphenoidotomy in CRSsNP patients following transnasal sphenoidotomy significantly reduces in size $(43.4 \%)$ within the first postoperative month, with a small improvement in size and then stabilisation occurring over the next five months. In our cohort, a baseline sphenoidotomy size of $61.3 \mathrm{~mm}^{2}$ (approx. three times the area of a $5 \mathrm{~mm}$ ear curette) did not result in ostium stenosis. About $50 \%$ of postoperative stenosed ostia experienced recurrent symptoms.

\section{Conflict of interest statement}

The authors declare no conflict of interest.

\section{Funding}

This research did not receive any specific grant from funding agencies in the public, commercial, or not-for-profit sectors.

\section{Authors' contributions}

PP processed the experimental data, took the measurements 
and wrote the article. $\mathrm{KM}$ and $\mathrm{JC}$ gave final approval for the article. IK conceived the study, performed the operations and processed the experimental data.

\section{Ethical consideration}

The investigations were performed according to the Guidelines for Biomedical Studies Involving Human Subjects ("Helsinki Declaration"). The study protocol was approved by the Ethics Committee of Aristotle University of Thessaloniki, Greece $(\Delta 3 \beta / 49441 / 17-12-2018)$. All the subjects provided written informed consent.

\section{References}

1 Lee JM, Yip J. Extended sphenoid sinus antrostomy and radical sphenoidectomy. In: Adappa N, Palmer J, Chiu Al, editors. Atlas of endoscopic sinus and skull base surgery. Philadelphia, PA: Elsevier Inc.; 2019. p. 133. https://doi.org/10.1016/C2015-0-01193-5

2 Stankiewicz JA, Donzelli JJ, Chow JM. Failures of functional endoscopic sinus surgery and their surgical correction. Oper Tech Otolaryngol - Head Neck Surg 1996;7:297-304. https://doi.org/10.1016/ S1043-1810(96)80051-0

3 Khalil HS, Eweiss AZ, Clifton N. Radiological findings in patients undergoing revision endoscopic sinus surgery: a retrospective case series study. BMC Ear, Nose Throat Disord 2011;11:2-7. https://doi. org/10.1186/1472-6815-11-4

4 Richtsmeier WJ. Top 10 reasons for endoscopic maxillary sinus surgery failure. Laryngoscope 2001;111:1952-1956. https://doi. org/10.1097/00005537-200111000-00015

5 Snidvongs K, Pratt E, Chin D, et al. Corticosteroid nasal irrigations after endoscopic sinus surgery in the management of chronic rhinosinusitis. Int Forum Allergy Rhinol 2012;2:415-421. https://doi. org/10.1002/alr.21047

6 Lund VJ, Kennedy DW. Staging for rhinosinusitis. Otolaryngol Head Neck Surg 1997;117:35-40. https://doi.org/10.1016/ S0194-5998(97)70005-6

7 Rudmik L, Soler ZM, Hopkins C, et al. Defining appropriateness criteria for endoscopic sinus surgery during management of uncomplicated adult chronic rhinosinusitis: a RAND/UCLA appropriateness study. Int Forum Allergy Rhinol 2016;6:557-567. https://doi. org/10.1002/alr.21769

8 Nouraei SAR, Hajioff D, Almeyda J, et al. Measurement of absolute dimensions in endoscopic sinus surgery. Laryngoscope 2005; 115:889893. https://doi.org/10.1097/01.MLG.0000161450.81557.6D

9 Drahaman AMP, Henney SE. Using SNOT - 22 as a decision making tool in performing nasal surgery. Ceylon Journal of Otolaryngology 2015;4:26-29. http://doi.org/10.4038/cjo.v4i1.5226

10 Hopkins C, Oxon MA, Orlhns F, et al. The predictive value of the preoperative Sinonasal Outcome Test-22 score in patients undergoing endoscopic sinus surgery for chronic rhinosinusitis. Laryngoscope 2015;125:1779-1784. https://doi.org/10.1002/lary.25318

11 O'Hara J. How I do it: sample size calculations. Clin Otolaryngol 2008;33:145-149. https://doi.org/10.1111/j.1749-4486.2008.01668.x

12 Feng AL, Wesely NC, Hoehle LP, et al. A validated model for the 22-item Sino-Nasal Outcome Test subdomain structure in chronic rhinosinusitis. Int Forum Allergy Rhinol 2017;7:1140-1148. https://doi. org/10.1002/alr.22025

13 Musy PY, Kountakis SE. Anatomic findings in patients undergoing revision endoscopic sinus surgery. Am J Otolaryngol - Head Neck Med Surg 2004;25:418-422. https://doi.org/10.1016/j.amjoto.2004.06.002

14 Aust R, Stierna P, Drettner B. Basic experimental studies of ostial patency and local metabolic environment of the maxillary sinus. Acta Otolaryngol 1994;114:7-11. https://doi.org/10.3109/00016489409124315

15 Singhal D, Weitzel EK, Lin E, et al. Effect of head position and surgical dissection on sinus irrigant penetration in cadavers. Laryngoscope 2010;120:2528-2531. https://doi.org/10.1002/lary.21092

16 Konstantinidis I, Tsakiropoulou E, Vital I, et al. Intra- and postoperative application of Mitomycin $\mathrm{C}$ in the middle meatus reduces adhesions and antrostomy stenosis after FESS. Rhinology 2008;46:107-111.

17 Thomas WW, Harvey RJ, Rudmik L, et al. Distribution of topical agents to the paranasal sinuses: an evidence-based review with recommendations. Int Forum Allergy Rhinol 2013;3:691-703. https:// doi.org/10.1002/alr.21172

18 Schuschnig U, Keller M, Klopfer E, et al. Drug delivery to the nasal and paranasal cavities - critical cast dimensions and aerosol dynamics. Respiratory Drug Delivery 2008;1:227-238.

19 Hosemann W, Wigand ME, Dunker I. Normal wound healing of the paranasal sinuses: clinical and experimental investigations. Eur Arch Oto-Rhino-Laryngology 1991;248:390-394. https://doi.org/10.1007/ BF01463560

20 Thompson CF, Conley DB. What is the optimal maxillary antrostomy size during sinus surgery? Curr Opin Otolaryngol Head Neck Surg 2015;23:34-38. https://doi.org/10.1097/MOO.0000000000000128

$21 \mathrm{Yu} \mathrm{H}, \mathrm{Li} \mathrm{H}$, Chi F, et al. Endoscopic surgery with powered instrumentation for isolated sphenoid sinus disease. ORL 2006;68:129-134. https://doi.org/10.1159/000091269

22 Nada I, El-Sharnouby M, Abo-El-Ezz T. The role of local rotational flaps in minimizing sphenoidal and maxillary sinuses ostium stenosis. Egypt J Ear, Nose, Throat Allied Sci 2014;15:93-97. https://doi. org/10.1016/j.ejenta.2014.03.001

23 Thompson CF, DeConde AS, Chiu AG, et al. Mini-nasoseptal flap for recalcitrant sphenoid sinusitis. Am J Rhinol Allergy 2013;27:144157. https://doi.org/10.2500/ajra.2013.27.3860

24 Charakorn N, Snidvongs K. Chronic sphenoid rhinosinusitis: management challenge. J Asthma Allergy 2016;9:199-205. https://doi. org/10.2147/JAA.S93023

25 Möller W, Schuschnig U, Meyer G, et al. Ventilation and drug delivery to the paranasal sinuses: studies in a nasal cast using pulsating airflow. Rhinology 2008;46:213-220. 